\title{
Commentary: Unifocalization revision: Patches, patches, and more patches...
}

\author{
Sameh M. Said, MBBCh, MD, FACS
}

From the Department of Cardiovascular Surgery, Mayo Clinic, Rochester, Minn.

Disclosures: Author has nothing to disclose with regard to commercial support.

Received for publication Oct 14, 2018; accepted for publication Oct 15, 2018; available ahead of print Nov 20, 2018.

Address for reprints: Sameh M. Said, MBBCh, MD, FACS, Department of Cardiovascular Surgery, Mayo Clinic, 200 First St SW, Rochester, MN 55905 (E-mail: said.sameh@mayo.edu).

J Thorac Cardiovasc Surg 2018;158:546-7

0022-5223/\$36.00

Copyright (C) 2018 by The American Association for Thoracic Surgery

https://doi.org/10.1016/j.jtcvs.2018.10.072

Pulmonary atresia with ventricular septal defect and major aortopulmonary collateral arteries represents a real challenge to the congenital cardiac surgical community. Unifocalization is the process of changing this abnormal multicompartmental pulmonary vascular bed into a normal single compartment through surgical reconstruction. The aim is to unite all these multiple different sources of pulmonary blood flow into a uniform compartment, with the goal of having the lowest possible pulmonary arterial (PA) to right ventricular (RV) pressure ratio to ensure satisfactory long-term outcomes. Several surgical strategies have been proposed during the last 2 decades, ranging from staged repair ${ }^{1}$ to single-stage midline repair, as proposed by Hanley and colleagues. ${ }^{2}$ The debate has continued between PA branch rehabilitation ${ }^{3}$ and unifocalization. The fate of this unifocalized vascular bed is not clearly known; however, reoperations are the rule, and it is well-known that these beds require repeat interventions, whether by repeat operations or by cardiac catheterization with ballooning or stenting.

In their article in this issue of the Journal, Mainwaring and colleagues ${ }^{4}$ review 254 patients who underwent single-stage midline complete unifocalization and described their experience with reoperation for recurrent branch stenoses that required revision (48 patients; $18 \%$ ). Follow-up data were available for $85 \%$ of these patients, but there were no long-term data. This is another important addition from a leading group to the treatment of this challenging anomaly, and Mainwaring and colleagues ${ }^{4}$ are to be congratulated on their excellent outcomes.

In my mind, the initial unifocalization procedure is the most important one, because it sets up the path for what is happening next. The future of the patient's pulmonary vascular bed will depend on how it is managed in the first operation. We can see that with proper initial repair, most of these patients will do well. But we also have to realize that some of these patients will never reach complete repair. This group is luckily the smallest, and the question is how to identify this group early on to avoid unnecessary

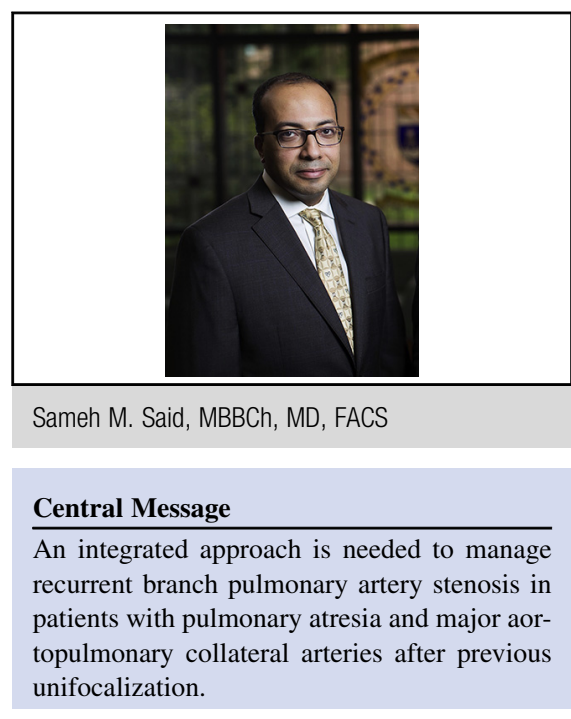

See Article page 534.

interventions. There is no doubt that unifocalization is a complex and long operation, and it is not without postoperative morbidities. Several dilemmas remain:

1. How do we identify those patients who are at risk for recurrent branch PA stenosis? These patients will need a different follow-up protocol. As an example, those who initially had unifocalization to a shunt appear to have shorter interval before the development of branch PA stenosis.

2. Is unifocalization of major aortopulmonary collateral arteries needed in all patients? Clearly, some patients will never have complete repair despite extensive unifocalization, and if we can identify this subset early on, an alternate strategy such as PA branch rehabilitation with a shunt or RV-PA conduit will perhaps be enough.

3. For recurrent branch stenoses, when do we pull the trigger for percutaneous interventions with balloon dilation or stenting? In the study of Mainwaring and colleagues, ${ }^{4} 25 \%$ of patients who underwent revision had only mild elevation in their ratio of PA pressure to aortic pressure. Although the lower the right ventricular pressure, the better the long-term outcomes, repeat operation is not without risks.

In conclusion, pulmonary atresia with ventricular septal defect and major aortopulmonary collateral arteries requires 
an integrated approach with proper initial unifocalization as the first step toward the formation of a healthy pulmonary vascular bed. Closer follow-up is mandatory, and a combination of interventional catheterization and repeat revision will be needed by most of these patients.

\section{References}

1. Puga FJ, Leoni FE, Julsrud PR, Mair DD. Complete repair of pulmonary atresia, ventricular septal defect, and severe peripheral arborization abnormalities of the central pulmonary arteries. Experience with preliminary unifocalization proced- ures in 38 patients. J Thorac Cardiovasc Surg. 1989;98:1018-28; discussion 1028-9.

2. Reddy VM, Liddicoat JR, Hanley FL. Midline one-stage unifocalization and repair of pulmonary atresia with ventricular septal defect and major aortopulmonary collaterals. J Thorac Cardiovasc Surg. 1995;109:832-44; discussion 844-5.

3. Soquet J, Liava'a M, Eastaugh L, Konstantinov IE, Brink J, Brizard CP, et al. Achievements and limitations of a strategy of rehabilitation of native pulmonary vessels in pulmonary atresia, ventricular septal defect, and major aortopulmonary collateral arteries. Ann Thorac Surg. 2017;103:1519-26.

4. Mainwaring RD, Patrick WL, Rosenblatt BA, Ma M, Kamra K, Arunamata A, et al. Surgical results of unifocalization revision. J Thorac Cardiovasc Surg. 2019;158:534-45.e1. 